\title{
Entity realism and singularist semirealism
}

\author{
Bence Nanay ${ }^{1,2}$
}

Received: 24 July 2015 / Accepted: 23 July 2016 / Published online: 9 August 2016

(C) The Author(s) 2016. This article is published with open access at Springerlink.com

\begin{abstract}
Entity realism is the view that 'a good many theoretical entities do really exist'. The main novelty of entity realism was that it provided an account of scientific realism that did not have to endorse realism about theories - the general proposal was that entity realism is noncommittal about whether we should be realist about scientific theories. I argue that the only way entity realists can resist the pull of straight scientific realism about theories is by endorsing a recent new player in the scientific realism debate: singularist semirealism.
\end{abstract}

Keywords Entity realism - Singularist semirealism - Scientific realism · Scientific antirealism · Theory change · Property-types · Property-tokens · Singular representations

\section{Theories}

The debate about scientific realism is in fact at least two separate debates (see NewtonSmith 1978; Hacking 1983 for taxonomies). One can be realist or antirealist about theories. Scientific realism about theories is the view that "scientific theories are either true or false independent of what we know: science at least aims at the truth and the truth is how the world is" (Hacking 1983, p. 27). In other words, science aims to give us literally true claims about the world and there is a fact of the matter, independent of us, about how the world is. This definition has two conjuncts: one about what science aims to do (see Rowbottom 2010 on what this means) and the other about the relation

\footnotetext{
Bence Nanay

bn206@cam.ac.uk

1 University of Antwerp, D 413, Grote Kauwenberg 18, 2000 Antwerp, Belgium

2 Peterhouse, University of Cambridge, Cambridge CB2 1RD, UK
} 
between scientific theories and the world. Scientific antirealists can deny either of these two conjuncts.

But this debate about theories is very different from, and logically independent of, the debate about unobservable entities. Realism about entities is the view that unobservable entities that scientific theories postulate really do exist. And, at least according to the proponents of entity realism, we can be realist about an unobservable entity a theory postulates without being realist about the theory that postulates it.

The aim of this paper is to examine the relation between these two debates. More precisely, I will examine what follows from entity realism for the realism versus antirealism debate about theories. The original proposal of entity realists was that entity realism is consistent with any view about theories-even straight antirealism. This view has been criticized more recently and it has been argued that entity realism in fact entails at least some form of scientific realism about theories (see Sect. 3).

My aim is to explore just how antirealist one can be about theories while endorsing entity realism. Entity realism (in spite of its name) is a compromise position between straight scientific realism and straight scientific antirealism. It's supposed to be the 'best of both worlds'. But any such realist/antirealist compromise position would need to maintain a fine balance. The question then is: how far can entity realism go in the antirealist direction?

And I will argue that we can go quite far in the direction of antirealism although not quite all the way. The most antirealist position that is still coherent with entity realism is singularist semirealism. Those who still have hopes for entity realism as an alternative to scientific realism about theories should endorse singularist semirealism.

The plan of the paper is the following. In Sect. 2, I outline entity realism and its various versions and methodological commitments. In Sects. 3 and 4, I consider the arguments against the claim that entity realism is consistent with antirealism about theories. In Sect. 5, I summarize the recent alternative to both scientific realism and scientific antirealism, singularist semirealism, and argue that it is the most antirealist we can get about theories while holding onto entity realism (Sects. 6, 7).

\section{Entity realism}

Entity realism is the view that, to quote Ian Hacking, "a good many theoretical ${ }^{1}$ entities do really exist" (Hacking 1983, p. 27, see also Cartwright 1983, p. 89). A very simple view, one might say. But the reason why entity realism was a major shift in the realism versus antirealism debate is that it pushed the debate about the truth of theories (or their aiming at the truth) in the background. Again, here is Hacking on the relation between entity realism and the realism versus antirealism debate about theories:

One can believe in some entities without believing in any particular theory in which they are embedded. One can even hold that no general deep theory about the entities could possibly be true for there is no such truth (Hacking 1983, p. 29).

1 I will use the less controversial term 'unobservable entities' instead of 'theoretical entities' in what follows. 
Hacking's point is twofold. First, one can be realist about observable entities and be noncommittal about the realism versus antirealism debate about theories. Entity realism may even be consistent with antirealism about theories. Second, and even more importantly, the question about realism that really matters is not the one about theories but the one about entities. And this seems to fit the actual scientific practice very well—scientists often do things with unobservable entities without (or before) having any firm theories about them.

So an experimental scientist may or may not be realist about theories, but as long as she conducts experiments with the help of unobservable entities, she must be realist about entities. As Einstein memorably said:

If you wish to learn from the theoretical physicist anything about the methods which he uses, I would give you the following piece of advice: Don't listen to his words, examine his achievements (Einstein 1934, p. 163).

Entity realism has been criticized for a number of reasons. I need to address some commonly voiced objections to the very idea of entity realism and especially to its alleged independence from realism about theories. I also need to examine the methodology entity realism is supposed to rely on.

Entity realism is a controversial view. What methodology entity realism should use is even more controversial. And Hacking's (and Cartwright's) insistence that one can be realist about entities and antirealist about theories is what is the most controversial about entity realism. It may be helpful to distinguish these three tenets of entity realism.

First, what I take to be the core commitment of entity realism is that the more evidence we have about the causal powers of $\mathrm{x}$, the more reason we have to be realist about $\mathrm{x}$. Taking causal powers as evidence for existence is hardly a very controversial move - the same connection does a lot of work in various metaphysical debates, for example, the one about the causal role of properties (Shoemaker 1979; Lewis 1983; Yablo 1992; Gillett and Rives 2005; Crane 2009). Jaegwon Kim even came up with a catchy label for this: "This we might call 'Alexander's Dictum': to be real is to have causal powers" (Kim 1993, p. 202). ${ }^{2}$ Although Hacking's view is routinely interpreted as a biconditional, namely, that we should be realist about $\mathrm{x}$ if and only if manipulating $\mathrm{x}$ leads to observable effects, I am not sure how strongly Hacking is really committed to the biconditional. What I take to be the core commitment of entity realism is that if we can manipulate an entity in a way that would lead to observable effects, we are justified to be realist about it. I want to remain neutral about whether he also claims that it is only if we can manipulate an entity in a way that would lead to observable effects that we are justified to be realist about it.

Second, what is more controversial is how we can find out about the causal powers of an entity - the methodology of entity realism. And here we get some variations within the entity realist camp-as how one should proceed in this question clearly depends on one's conception of causation in general. According to Nancy Cartwright,

\footnotetext{
2 Kim is not always very clear about whether being real is a necessary or sufficient or necessary and sufficient condition for having causal powers. The more important direction of entailment from the point of view of entity realism is that if something has causal powers, we can conclude that it exists (many applications of Alexander's Dictum focus on the other direction, see, e.g., Cargile 2003).
} 
we have reason to endorse realism about entity $\mathrm{x}$ if $\mathrm{x}$ figures essentially in causal explanations of observable phenomena (Cartwright 1983).

Ian Hacking's view is slightly different: if we can manipulate $\mathrm{x}$ in such a way that this has direct influence on observable phenomena, we have reason to endorse realism about entity x. As his famous one-liner goes, "so far as I'm concerned, if you can spray them, they are real" (Hacking 1983, p. 23). I prefer another, less famous, but somewhat more informative, one-liner: "When we use entities as tools, as instruments of inquiry, we are entitled to regard them as real" (Hacking 1989, p. 578). Or, even more informatively:

We are completely convinced of the reality of electrons when we regularly set out to build and often enough succeed in building new kinds of device that use various well-understood causal properties of electrons to interfere in the more hypothetical parts of nature (Hacking 1983, p. 265).

Hacking and Cartwright give two different ways of cashing out the very same idea: namely, that discovering the causal properties of an entity is what justifies realism about this entity. But they offer very different methodologies for establishing these claims. I will focus on Hacking's methodology mainly because Cartwright's relies on a fairly specific stance on the relation between causal explanation and causation that is easy to attack (see, e.g., Psillos 2008). But I will come back to Cartwright's version in Sect. 7.

When we are assessing entity realism, we should use the following methodology then: if we can manipulate 'well-understood causal properties' of a certain kind of entity in a way that would have direct observable effects, we can be convinced of the reality of this kind of entity. This, of course, leaves open the question about how we can manipulate unobservable entities (see Giere 1988, pp. 111-140).

These core commitments of entity realism have been criticized both for being too restrictive and for being too inclusive (see Shapere 1993 and Gelfert 2003, respectively). My aim in this paper is to assume that the core commitments of entity realism are correct and examine what entity realism entails when it comes to the debate about realism versus antirealism about theories. The promise of entity realism was that it does not presuppose realism about theories. My aim in the next sections is to assess the plausibility of this claim.

\section{Entity realism and theories}

The real controversy about entity realism comes from the proposal that entity realism does not presuppose realism about theories-this is the aspect of entity realism that the scientific realist camp finds difficult to swallow. As Erman McMullin sums up, according to entity realism, we may "know that the electron [exists], even though there is no similar assurance as to what it is" (McMullin 1984, p. 63, see also the critical analysis in Morrison 1990; Resnik 1994; Massimi 2004).

This may sound as a blatant contradiction: how can we know that $\mathrm{x}$ exists if I have no idea about what $\mathrm{x}$ is? If I really have no idea about what $\mathrm{x}$ is, then $\mathrm{I}$ am not in the position to manipulate it. And if I do know enough about x so that I can 
manipulate it, then I am already applying a theory to $\mathrm{x}$. This general line of argument against the claim that entity realism doesn't presuppose realism about theories has become the standard way of dismissing entity realism as a genuinely new option in the old-fashioned realism versus antirealism debate. Here is David Resnik:

'the experimental realist can only have knowledge about theoretical entities if she assumes that the theories which describe those entities are at least approximately true; and ...that experimentation is not nearly as theory-free as Hacking maintains' (Resnik 1994, p. 395)

And again:

one cannot rationally claim to use a theoretical entity as a tool of inquiry without some evidence, or justification... Hence, if one regards an entity as a tool of inquiry, one must also claim that its place in the world's causal structure explains some phenomena. (Resnik 1994, p. 404)

And here is Psillos really hammering home the point:

the distinction between being realist about entities and being realist about theories is misconceived. It may well be the case that electrons exist, even though some (or most) of our descriptions associated with the term 'electron' are false. But the issue at stake is different. It is this: can we assert that electrons are real, i.e. that such entities exist as part and parcel of the furniture of the world, without also asserting that they have some of the properties attributed to them by our best scientific theories? I take it that the two assertions stand or fall together. (Psillos 1999, p. 256)

Experimenters do not know what exactly it is that they manipulate, although they can know that they are manipulating something, unless they adopt some theoretical description of the entities they manipulate. [...] What makes electrons different from, say, neutrinos is that they have different properties, and obey different laws. One should rely on these theoretical descriptions in order to manipulate these entities effectively and exploit their causal powers. (Psillos 1999, p. 256)

If it is not admitted that some theoretical descriptions of the causal powers of the entity are correct, then the mere positing of the entity cannot produce any sound expectations about which phenomena are due if and when this entity is manipulated (Psillos 1999, p. 257.)

The very same process is involved in accepting the reality of an entity, and in accepting the (approximate) correctness of its theoretical description. (Psillos 1999, p. 257.)

These are by no means isolated examples. (see also Musgrave 1996's florid way of making basically the same point). The received wisdom about entity realism seems to be that if we apply pressure, it will become a plain and ordinary version of scientific realism about theories. This is great news for the realist, of course. They can use 
Hacking's and Cartwright's emphasis on actual scientific practice and experimentation to support old-fashioned scientific realism about theories. It is also bad news for those who wanted to carve out an intermediary position between scientific realism and scientific antirealism.

This was the great attraction of entity realism: it was the first of the 'best of both worlds' accounts in the scientific realism debate-it tried to combine the appeal of scientific realism and the appeal of scientific antirealism. If the standard critical line on entity realism is correct, this intermediary position is in fact an unstable position: if we make explicit what it is that we need to know about $\mathrm{x}$ in order to manipulate it, entity realism reverts to straight scientific realism about theories.

\section{Entities, properties, theories}

How can the entity realist respond to these charges? The most influential way of arguing that entity realism is consistent with antirealism about theories is to bring in some heavy-duty metaphysical artillery. Hacking himself suggested that entity realism would find some metaphysical support in the Kripke- and Putnam-style causal theories of reference (Kripke 1972; Putnam 1975): we can refer to something even though it has none of the properties we take it to have (Hacking 1982, pp. 157-159; 1983, pp. 75-91). But then we can refer to unobservable entities even though we have no idea what they are.

It is not at all clear that this appeal to Kripke/Putnam-style theories of reference would in fact help the entity realist (see, e.g., Hardin and Rosenberg 1982; Laudan 1984; Chakravartty 2007, Chap. 2). It has been argued that by endorsing the Kriple/Putnam account of reference (and with it the Kripke/Putnam line on natural kinds), entity realism is, again, forced to be realist about theories. As Resnik summarizes:

while [Putnam's semantic theory] establishes the cogency of Hacking's metaphysical part of theory-free entity realism, it does not go very far in supporting the epistemological aspect of this view. Theory-free entity realism is on epistemologically solid ground-it can give us knowledge-only if we know that the entities to which we refer are natural kinds; that is, we know that they are fundamental parts of the world's causal structure (Resnik 1994, p. 407).

So the appeal to Kripke/Putnam-style theories of reference doesn't seem to be able to salvage entity realism from collapsing into straight scientific realism about theories. ${ }^{3}$

Another option for the proponents of entity realism is to take a step back and weaken the original claims of entity realism (or, as some may argue, by returning to the original version of entity realism, dispelling some of its misinterpretations, see Clarke 2001). The general strategy here would be to admit that entity realism does

3 An ad hominem remark, but it is also unclear how this metaphysical framework is consistent with Hacking's later stance on natural kinds, see Hacking (1990, 1991, 2007a) and also Hacking (2007a, 2015) on Hacking's take on Putnam's theory of reference more specifically. 
presuppose some degree of generalizations about entities. But it does not presuppose fully-fledged theories.

This way of framing entity realism can find some support in Hacking's book, where he talks about 'home truths' (Hacking 1983, p. 265). Home truths are something all experimenting scientists need to rely on in order to be able to manipulate anything. But they do not constitute a theory - they can be considered to be disconnected pieces of truth about the praxis of experimentation and, to quote Margaret Morrison, they "do not constitute anything like the kinds of complex frameworks that are normally taken to be definitive of a theory" (Morrison 1990, p. 1).

Another version of this way of defending entity realism comes from Steven Clarke:

Entity realists have no objection to low-level generalisations about entities; in fact they rely on the viability of these to give sense to the descriptions of entities that they wish to endorse. (Clarke 2001, p. 704)

With both versions of this way of defending entity realism, the general worry is that we would need to have some principled distinction between 'home truths' and theoretical truths or between 'low-level generalizations' and theories per se. These home truths or low-level generalizations cannot be too homey or too low-level, otherwise they wouldn't allow us to manipulate entities. But they cannot be too high-level either, otherwise the threat of collapsing into straight realism about theories is not avoided at all.

Anjan Chakravartty's semirealism could also be thought to be a version of this general line of defending entity realism. Chakravartty distinguishes between an entity's detection properties and auxiliary properties (Chakravartty 1998, pp. 394395; Chakravartty 2007, pp. 47-54). As he says:

Detection properties are causal properties one has managed to detect; they are causally linked to the regular behaviours of our detectors. Auxiliary properties are any other putative properties attributed to particulars by theories (Chakravartty 2007, p. 47).

It is important that Chakravartty intends this distinction to be an epistemic one: we may discover later that some of the auxiliary properties are in fact detection properties. Chakravartty's argument is that entity realists should be realist not just about their entities but also about their detection properties. They can and should be agnostic about the reality of the entity's auxiliary properties.

One way in which we can pull together these three very different accounts of salvaging entity realism (home truths, low-level generalizations, detection properties) is with the help of a distinction Michael Devitt makes between entity realism and what he takes to be the view entity realism needs to be distinguished from in order to count as a distinctive view (that would not collapse into straight scientific realism about theories). This view entity realism needs to be distinguished from is the following:

science is mostly right, not only about which unobservables exist, but also about their properties (Devitt 1991, p. 46). 
Now, all the three strategies of salvaging entity realism I considered insist on a 'divide and conquer' strategy about these properties. If science says nothing about any of the properties of unobservable entities, then it does not allow for manipulation and experimentation. If it specifies all the properties of the unobservable entity (according to a theory), then this turns entity realism into straight realism about theories. So there is not a lot of elbow-room for the defenders of entity realism: they should say that science should specify some, but not all properties of unobservable entities. It should specify the home truths about the unobservable entities, but not theoretical truths. It should specify low-level generalizations, but not theoretical generalizations. And it should specify the entity's detection properties, but not its auxiliary properties.

While this seems to be the logical move for those who want to defend entity realism, I don't think it is a very successful one. More specifically, I do not see how this move blocks the realist's insistence that entity realism entails realism about theories. The realist response would be that granting reality to home truths, low-level generalizations and detection properties already forces one to be realist about theories. Low-level generalizations are generalizations nonetheless - it is difficult to see what prevents them from being theories - maybe low-level theories, but theories nonetheless.

Remember that according to Psillos, the real question about entity realism was this: "can we assert that electrons are real, i.e. that such entities exist as part and parcel of the furniture of the world, without also asserting that they have some of the properties attributed to them by our best scientific theories?" (Psillos 1999, p. 256) If this is the make or break criterion, then appeal to home truths, low-level generalizations and detection properties will not work. The home truth version, the low-level generalization version and Chakravartty's version of entity realism all need to say that unobservable entities 'have some of the properties attributed to them by our best scientific theories'. But this is enough for the proponents of straight realism about theories to conclude that these versions of entity realism are really closet realist about theories.

Let us go back to Devitt's contrast between entity realism and the view according to which:

science is mostly right, not only about which unobservables exist, but also about their properties (Devitt 1991, p. 46).

This contrast is indeed something that the entity realist needs to have a coherent story about. And Devitt's emphasis on properties is also the right way of formulating the contrast. Being realist about the bare particular is not enough. It does not allow for experimentation. But if we allow for realism about any property-types, we are already in the domain of theories (as property-types are what theories attribute to entities $^{4}$ ) — that is what I take to be Psillos's point.

\footnotetext{
4 I take it to be an uncontroversial minimal requirement on theories that they contain laws or at least generalizations and I also take it to be uncontroversial that laws and generalizations are about propertytypes. See, for example, David Lewis, who famously said that "laws and natural properties [that is, natural property-types] get discovered together" (Lewis 1983, p. 368). It should be emphasized that Lewis is not an isolated case here: David Armstrong said that scientific laws are "hypothesized to relate types not tokens" (Armstrong 1993, p. 422). But I do want to acknowledge that one can use the term 'scientific laws' in a less demanding manner, which does not make them dependent on property-types, say, as maximally general
} 
But these even further restrictions of the elbow-room of entity realism also make it possible to see where entity realism can turn to for some support. Entities are particulars. We should be realist about them, if we are to be entity realist. But propertytypes are not particulars - they are types: abstract entities. If we are realist about property-types, this is Psillos's warning, we are being realist about theories.

Put this way, it seems clear what entity realists should say. Yes, being realist about bare particulars is not enough. We should also be realist about property tokens. Property tokens are also particulars. And being realist about particulars only does not amount to being realist about theories. Importantly, we can be realist about property tokens without being realist about property types. And as long as we are not realist about property types, we can fend off realism about theories. This way of thinking about the relation between property tokens and property types presupposes a specific view about the metaphysics of properties. But if we accept this metaphysical picture, we can be realist about the unobservable entity and its property tokens - and this realism is thick enough to allow us to manipulate these entities. But we can still be antirealist about property types and with it about theories.

Let us return to the Devitt quote one last time in order to disambiguate it. Here is a plausible way of formulating entity realism:

science is mostly right, not only about which unobservables exist, but also about their property tokens.

And this view needs to be contrasted with the much stronger claim of straight scientific realism about theories:

science is mostly right, not only about which unobservables exist, but also about their property types.

So entity realism can be consistent with antirealism about theories as long as it says that

science is mostly right, not only about which unobservables exist, but also about their property tokens, but not their property types.

This may seem sketchy, but luckily there is a recent contribution to the realism versus antirealism debate that defends exactly this position-singularist semirealism (Nanay 2011a, 2013). Singularist semirealism and entity realism are allies. Further, it seems that the only way in which entity realism can steer clear of straight realism about theories is by endorsing singularist semirealism.

\section{Singularist semirealism}

Singularist semirealism is the view that there is always a fact of the matter about whether the singular statements science gives us are literally true, but there is no fact

Footnote 4 continued

explanatory generalizations about particular entities. I am assuming that this is not the sense in which Psillos uses the term. 
of the matter about whether non-singular statements are literally true (Nanay 2011a, 2013). I want to do some fine-tuning of these claims and highlight the very specific metaphysical picture this view presupposes.

First, not all scientific representations are statements, so we need to broaden the scope of singularist semirealism to include nonlinguistic representations. In other words, we need to make a distinction between singular and non-singular representations. Singular representations attribute property-tokens (to particulars). Non-singular representations attribute property-types (to particulars or sometimes to other propertytypes). Here is a non-singular representation: "Japanese cars are reliable". Here is a singular representation: "my Honda in front of my house has this shade of grey". Only particulars show up in a singular representation, whereas non-singular representations are not exclusively about particulars.

Singularist semirealism gives up scientific realism about property-types and nonsingular representations but keep scientific realism about property-tokens and singular representations. Thus the label: singularist semirealism. There are many wrinkles that the singularist semirealist needs to iron out. First, keeping scientific realism about singular representation means that there is always a fact of the matter about whether singular representations are correct - there is always a fact of the matter about whether a particular has a certain property-token. But what does it mean to give up scientific realism about non-singular representations? Here things get a bit more complicated. A more precise statement of this would be that there is no fact of the matter about whether not-analytically-correct and not super-determinable non-singular representations are correct (see Nanay 2013).

Further, this singularist semirealist proposal is clearly deeply rooted in some fairly specific metaphysical picture about the relation between property-types and propertytokens. I will say more about this metaphysical picture in the next section.

Given the nature of the singularist semirealist proposal, some will find this view too realist and some others will find it too antirealist. But the aim is to capture the 'best of both worlds' (Worrall 1989). Singularist semirealism, for example, denies that we should be realist about laws-laws are about property-types (as David Lewis famously said, "laws and natural properties [that is, natural property-types] get discovered together" (Lewis 1983, p. 368)) and it is part of the singularist semirrealist proposal that there is no fact of the matter about property-types. But if there is no fact of the matter about property-types, then there is no fact of the matter about laws (that connect property-types) either. And there is no fact of the matter about general causal claims either (as these connect property-types as well). This pushes singularist semirealism in the antirealist direction.

But being realist about property-tokens and singular representations means that we can also be realist about singular causal claims - as singular causal claims are about entities and their property-tokens- they are not about property-types. So singularist semirealism can be entirely realist about causation-as long as causation is taken to be singular causation (see also the Section 7 about the consequences of this move for entity realism). This pushes singularist semirealism in the realist direction.

Singularist semirealism also promises to do better than straight antirealism when it comes to the allegedly most important realist objection: the 'no miracles argument'. Singularist semirealism has a straightforward response to the argument that it is only 
scientific realism "that doesn't make the success of science a miracle" (Putnam 1975, p. 73, see also Smart 1968, p. 39, see also Stanford 2000, pp. 269-270; Lyons 2003; Devitt 2008; Musgrave 1988; Van Fraassen 1980). If there is always a fact of the matter about the correctness of singular representations and singular causal claims, then we can explain the success of science very well relying on the literal correctness of singular representations and singular causal claims, even while remaining antirealist about non-singular representations. According to singularist semirealism, propertytypes are our ways of grouping property-tokens. Some groupings are more useful from a pragmatic point of view than others: they allow us to make better predictions and explanations. And, importantly, what is supposed to be grouped by these propertytypes are property-tokens and there is, again, always a fact of the matter about whether a particular has a property-token. But if this is true, then the ultimate argument against scientific antirealism does not work in the case of singularist semirealism.

And singularist semirealism promises to do better than straight realism when it comes to the allegedly most important antirealist objection: the 'pessimistic metainduction' or objection from theory change (Laudan 1981; Psillos 1999). Unlike straight antirealism, singularist semirealism can point to something that remains unchanged even in radical theory change: the underlying, supposedly correct singular representations and singular causal claims. ${ }^{5}$ Property-types and the theories that postulate them come and go, but the singular representations and singular causal claims are here to stay. I am not convinced that either of these arguments are as powerful as they are made out to be. But those who are moved by the force of them should consider singularist semirealism to be a very attractive alternative to straight scientific realism and to straight scientific antirealism.

What I propose is something seemingly odd: in order to tackle the debate about the reality of unobservable entities, I invoke another debate about the reality of abstract entities (that is, property-types). In other words, in order to defend entity realism, we should turn to singularist semirealism.

Let us see how singularist semirealism can help entity realism. Entity realists are realist about unobservable entities. But in order to allow them to manipulate these unobservable entities, they should also be realist about more than just the bare particular. They should also be realist about the property tokens of these unobservable entities. They should be realist about singular representations then. And what is needed for successful manipulation of unobservable entities is exactly to be realist about them and their property tokens - to be realist about singular representations.

\footnotetext{
5 In this respect, singularist semirealism resembles structural realism, according to which what is preserved through theory change is the structure (Worrall 1989; Ladyman 1998). According to singularist semirealism, what are preserved through theory change are singular representations. I think this is the end of the parallel between singularist semirealism and structural realism. From the point of view of this paper, what is the most relevant is that it's been debated whether structural realism is consistent with entity realism. While on the face of it structure (at least on some interpretation of what this concept means) is exactly what entity realism is noncommittal about, it has been argued that this prima facie take on the relation between entity realism and structural realism is mistaken (see esp. Chakravartty 1998, 2007; Dorato 2000). I want to remain neutral about whether entity realism is consistent with structural realism. The aim of the paper was to argue that entity realism is not only consistent with singularist semirealism, but it presupposes singularist semirealism if it want to avoid collapsing into straight scientific realism about theories.
} 
Hacking talked about 'home truths' that allow the experimenter to manipulate entities (Hacking 1983, p. 265). We can now put a singularist semirealist gloss on what these home truths are: they are singular representations. We have seen that it is difficult to come up with a principled way of keeping apart home truths and theoretical truths (see also Gelfert 2003). But if we accept the singularist semirealist framework, then it becomes very easy to delineate home truths from theoretical truths. Home truths are about singular representations, whereas theoretical truths are about nonsingular representations. The central idea of singularist semirealism is exactly to be realist about the former but antirealist about the latter.

And this distinction is very different from the one Chakravartty makes between two different kinds of nonsingular representations - ones that attribute detection property types and ones that attribute auxiliary property types. My distinction is between representations that attribute property types (detection or auxiliary) on the one hand (which entity realism should be antirealist about) and representations that attribute property tokens (which entity realism should be realist about).

To put it very simply, experiments are done on particulars with property-tokens. No experiment is done on property-types. Experimenters manipulate property-tokens, not property-types. Of course, on the basis of the manipulation of property-tokens, science postulates models or laws or general causal claims that are about property-types, but this process needs to start with the attribution of property-tokens.

One may worry whether singularist semirealism really helps entity realism resist the lure of realism about theories. Importantly, how does the scientist identify what property-token to manipulate? Wouldn't she need to already group the property token under a property-type to even begin to manipulate it? But if property-types are used to identify what property-tokens are manipulated, then how would singularist semirealism-infused entity realism not collapse into straight realism about theories?

Again, let us go back to the original insight that experiments are done on propertytokens and not on property-types and that what we are manipulating in experiments are property-tokens, not property-types. In the experiment Hacking talks about, what does the experimenter need to know and do in order to spray the niobium ball with electron?

My answer is that there is no reason to think that the experimenter would need to be realist about any of the property types of the electron (or of the niobium ball or anything involved in this experiment). All she needs is some knowledge of previous attempts at spraying niobium balls with electron. Some of these attempts were successful, some others, no doubt, unsuccessful. She should try to spray the niobium ball in a way that is more similar, in the relevant respects, to the previous (token) successful attempts. But this is consistent with the singularist semirealist story: the experimenter could consider property-types to be convenient and pragmatically useful ways of grouping property tokens. When she needs to identify those property tokens of the unobservable entity that she is trying to manipulate, she can do so without being realist about property-types.

In other words, the 'home truths' that allow the experimenter to manipulate unobservable entities are about entities and their property-tokens. The experimenter may need to appeal to property-types in order to identify the property-tokens to be manipulated, but there is no reason why she would need to be realist about these property-types (and not think of them as convenient and pragmatically useful ways of grouping prop- 
erty tokens). Manipulation does require more than being realist about bare particulars. But it does not require more than being realist about particulars - entities and propertytokens. Manipulation does not presuppose realism about property-types, hence, it does not presuppose realism about theories either.

Entity realism was clearly inspired by actual scientific practice; both Hacking and Cartwright are very clear about this. Scientists themselves are entity realist and it is not at all clear to what extent they are realist about theories. Singularist semirealism was also inspired by actual scientific practice: by the methodology of population thinking in biology (Mayr 1959/1994; Nanay 2010a). Entity realism and scientific semirealism are natural allies. And, as I tried to argue, singularist semirealism can stop entity realism from sliding back into straight realism about theories.

\section{The metaphysical price of entity realism (and singularist semirealism)}

The maneuver I described in the last section that entity realism can help itself to if it endorses singularist semirealism would only work if we had a fairly specific metaphysical picture about the relation between property types and property tokens. The aim of this section is to spell out this metaphysical picture and argue that it is not particularly crazy.

The metaphysical assumption we need to make to get singularist semirealism off the ground is that there is no fact of the matter about whether a property-token belongs to, or is an instantiation of, a property-type, as property-types are our own groupings of property-tokens. Property-tokens are out there, independently of us. Property-types aren't. In other words, only particulars exist out there, independently of us: propertytokens are particulars so they exist out there, independently of us. Property-types are not particulars: they do not exist independently of us: they are the product of our grouping particulars in a certain way.

It may be helpful to think of this metaphysical view as a version of trope nominalism - the view that tropes exist, whereas universals don't. Tropes are particular property tokens that are logically incapable of being present in two different particulars. So trope nominalism would be the view that these tropes exist, but universalsproperty-types that can be present in two particulars-don't exist.

Some versions of trope nominalism can and do talk about property-types: propertytypes are the resemblance classes of tropes (Bacon 1995, p. 18; Williams 1953, p. 81; Campbell 1981, p. 134). But then the logical priority of property tokens versus property-types is an open question even within the trope nominalist framework. A trope nominalist could still take property-types (that is, the resemblance classes of tropes) to be logically prior and tropes themselves as somehow derived from them (if there is a fact of the matter about the 'joints' of trope resemblance classes). The version of trope nominalism that singularist semirealism relies on denies this: according to this version of trope nominalism, property-tokens (tropes) are logically prior to property-types (the resemblance classes of tropes), so much so that only property-tokens (tropes) exist out there, independently of us; property-types (the resemblance classes of tropes) are the product of our grouping them in a certain way.

Would accepting this metaphysical picture be too high a price to pay for defending a specific view in the scientific realism vs. scientific antirealism debate? I don't think so. 
This metaphysical picture is not at all extravagant: in fact, it is the opposite of extravagant. It states that only particulars exist. As property-types do not exist, there is no fact of the matter about them. And the same goes for the resemblance classes of tropes.

But maybe not everyone finds the trope-talk helpful. We can formulate the metaphysical view that singularist semirealism relies on (and that entity realism should also rely on) without any reference to tropes.

There are two ways of thinking about the logical relation between property-tokens and property-types (and, as a result, about the logical relation between singular and non-singular representations). One view about this relation is that property-types (and, as a result, non-singular representations) are logically prior: property-tokens are to be derived from property-types (as their instantiations) and singular representations are to be derived from non-singular ones. This is a tempting picture given that language tends to give us non-singular representations and we, philosophers, especially analytic philosophers, take language very seriously. But maybe we should resist this temptation - the question about the relation between property-types and propertytokens is a metaphysical question and it is not at all clear why the fact that we are language-users should be a relevant consideration in settling metaphysical disagreements.

According to the alternative view, it is property-tokens (and, as a result, singular representations) that are logically prior: Property-types are to be derived from propertytokens and non-singular representations are to be derived from singular ones-and the only way to derive them is by means of the pragmatic usefulness of the nonsingular representations that are based on singular representations. This is the broadly nominalist singularist semirealist picture.

More slowly, think of property-tokens as points in a property-space (see Quine 1969, Clark 2000 on the concept of property-space-see also Lewis 2001, pp. 385386). Some pairs of property-tokens resemble each other more than others: they are closer together in this property-space. Property-types are regions in the property-space.

One picture about this property-space is that there is a fact of the matter about where the 'true' boundaries of the regions of this property-space lie: there is a fact of the matter about where one property-type ends and where the other begins.

Another, alternative, picture is the following. Some pairs of property-tokens are closer together in the property-space: they resemble each other more than others. ${ }^{6}$ But

\footnotetext{
6 Someone could question this claim—attacking singularist semirealism from a straight antirealist direction. More precisely, one could bring in Goodman-style considerations about whether there is ever a fact of the matter about resemblance, even between two tokens. And here it is important that the resemblance in question is between two tokens of a specified property, say, length or weight, in a property-space where there are only tokens of this specific property. So while we can agree with Goodman that any two particular entities can be said to resemble each other and do so to the same extent, when it comes to tokens of one specified property in a specified property-space, the same objection doesn't work. There may not be a fact of the matter about whether a rabbit resembles an electron more than a neutrino, but there is a fact of the matter about whether the weight-token of a rabbit is closer to the weight-token of an electron or the weight-token of a neutrino in the weight property-space.

But one could push this worry even further. Depending on how we choose the axes of the 'propertyspace', the similarities between property tokens will look very different. Two points in a property-space with 'grue' and 'bleen' axes may be very similar whereas in another property-space with 'blue' and 'green' axes they may not be. I want to sidestep this problem with the help of a mathematical procedure called 'Principal
} 
property-types are our arbitrary ways of delineating regions of this property-space and the way we group property-tokens together depends on our interests. In other words, there is a fact of the matter about how similar any two property-tokens are. But there is no fact of the matter about whether a property-token belongs to a property-type (see Goodman 1955; Taylor 1993, 2004 and Nanay 2009, 2010a,b, 2011a, b, 2013 for versions of this general view).

To use an old (Hacking-inspired) analogy, property-tokens could be thought of as stars and property-types as constellations (Darwin 1859, p. 397; Cournot 1851; Goodman 1978 see Hacking 2007a for a good summary). There is a fact of the matter about the distance between any two stars, but the constellations of stars, like that Cassiopeia, are our own arbitrary groupings of some stars. As Ian Hacking says, "they are convenient for navigators but the stars are grouped together by people, not nature" (Hacking 2007a, p. 225). Similarly, there is a fact of the matter about the degree of resemblance between any two property-tokens, but, to paraphrase Hacking, propertytypes are property-tokens 'grouped together by people, not nature'.

Note that if someone thinks that there is a fact of the matter about where the 'true' boundaries of the regions of this property-space lie, then these true boundaries are supposed to justify the pragmatic relevance of carving up the property-space this way. If there is an objective, mind-independent common denominator among some property-tokens, then treating them as instantiations of one and the same property-type will clearly be pragmatically useful. But the singularist semirealist picture proceeds the other way round. Some property-tokens are pragmatically useful to group together. And this explains why we consider these property-tokens to be instantiations of the same property-type. In the singularist semirealist picture, it is not the objective, mindindependent existence of property-types that explains why these property-types are pragmatically useful, but our pragmatically useful way of grouping property-tokens constitutes what we consider property-types.

The singularist semirealist view is that property-types are our grouping of property-tokens. Quick clarifications: first, could we group together really distant property-tokens, if we wanted to? We could. But these groupings would be very unlikely to serve any kind of practical purpose. We could group together stars from various distant parts of the firmament, but that would hardly be called a constellation, let alone a constellation that could serve any practical purpose. Second, shouldn't we group together exactly resembling property-tokens? The answer is that we should. But

\footnotetext{
Footnote 6 continued

Component Analysis', which is used to transform a high dimensional space where data are plotted into a space with as few dimensions as possible that still retains all the variability in the data. In the high dimensional space the axes may code for correlated variables, whereas in the new property space only contain axes of linearly uncorrelated variables, which are called principal components (thus the label 'Principal Component Analysis') (see Jolliffe 2002; Eriksson et al. 2006 for overviews of the mathematics behind Principal Component Analysis, Pearson 1901 for the origins thereof and Macpherson 2014 for an application within philosophy). So we can resolve the puzzle of the apparent arbitrariness of axes in singularist semirealism by adding all the possible axes together (not just grue and bleen, but all kinds of wild combinations thereof), creating a vastly multi-dimensional property-space (with vastly cross-dependent axes) and apply Principal Component Analysis to simplify it to a property-space with principal components. More needs to be said on this, but for a similar use of the Principal Component Analysis that I could plug in here, see Macpherson (2014) (who uses Principal Component Analysis for tacking the problem of individuating the senses).
} 
the property-types this (obvious) grouping would give rise to (that is, super-determinate property-types) are of not much use in actual scientific practice. Super-determinate property-types, if they really are super-determinate, are unlikely to appear in the claims scientists make: no two rabbits have exactly the same super-determinate properties (see Mayr 1959), and maybe not even two atoms do. Scientists often (arguably, always) consider two property-tokens to be 'the same' for their purposes even if they do not belong to, or are not instantiations of, the same super-determinate property-type.

Hacking wanted to support entity realism and, more precisely, the claim that entity realism does not need to endorse straight realism about theories with the help of metaphysics - by turning to Kripke/Putnam-style theories of reference. There is, indeed, little hope of keeping apart entity realism and realism about theories without bringing in some kind of metaphysical heavy artillery. But I think that Hacking turned to the wrong kind of metaphysical help. Instead of relying on industrial strength essentialist theories (again, see a more nuanced take on how Putnam differs from Kripke in Hacking 2007b, 2015), he should have sought help in the opposite direction: from the nominalists.

I did not defend this broadly nominalist metaphysical picture about the relation between property-types and property-tokens here. My aim was to trace the metaphysical costs of salvaging entity realism with the help of singularist semirealism. And the least we can say is that this cost is not more off-putting than endorsing Kripke/Putnamstyle theories of reference.

\section{Conclusion}

I focused on Hacking's version of entity realism. The reason for this was that his emphasis on manipulation provides a direct link to singularist semirealism because what scientists are manipulating are property-tokens. But in this last section I want to return to Nancy Cartwright's version of entity realism briefly and point out that singularist semirealism can be helpful for her version as well.

According to Cartwright, we have reason to be realist about $\mathrm{x}$, if $\mathrm{x}$ figures essentially in a causal explanation (Cartwright 1983, 1999). I stayed away from this formulation because of the raging debates about what causal explanations are and about the relation between causation and causal explanations. But now, with the singularist semirealist toolkit at hand, we can return to this way of thinking about entity realism.

Here is Psillos's argument against Cartwright's entity realism:

In offering causal explanations we are committed to much more than entities. We are also committed to laws, unless of course there is a cogent and general story to be told about causal explanation that does not involve laws. Note that it is not a reply to my charge that there might be singular causal explanation. This is accepted by almost everybody-given the right gloss on what it consists in. Nor would it be a reply to my charge that, occasionally, we do not rely on laws to offer a causal explanation. A suitable reply would have to show that causal explanation is totally disconnected, from laws. (Psillos 2008, p. 171) 
Psillos is entirely right about this, but I want to turn what he seems to intend as a reductio argument into an argument for how Catwright's entity realism also presupposes singularist semirealism. Yes, in offering causal explanations, we are committed to more than entities. We are also committed to property-tokens. But if the causal explanation makes singular causal claims, then this is all we need to be committed to. And this is consistent with (in fact, it entails) the claim that 'causal explanation is totally disconnected from laws'.

Cartwright faces a choice. If she allows property-types into her causal explanations, Psillos is right that she has now way of avoiding being committed to laws - and with that to realism about theories. I assume that this is not the direction she wants to go. But the other option would be to endorse singularist semirealism: singularist semirealist causal explanations only commit to the reality of property-tokens. Realism about property-tokens allows us to make literally true or false singular causal claims. But if we are only realist about property-tokens and not about property-types, then this also keeps away any realism about laws (because laws are about property-types). The only interpretation of Cartwright's entity realism that can avoid being realist about laws is one provided by singularist semirealism.

Acknowledgements This work was supported by the FWO Odysseus grant [G.0020.12N] and the FWO Research grant [G0C7416N]. I presented parts of this material at the University of British Columbia, University of Tilburg, University of Cambridge and Lingnan University and I'm grateful for the comments I received on these occasions. I am also grateful for the comments of the referees at this journal.

Open Access This article is distributed under the terms of the Creative Commons Attribution 4.0 International License (http://creativecommons.org/licenses/by/4.0/), which permits unrestricted use, distribution, and reproduction in any medium, provided you give appropriate credit to the original author(s) and the source, provide a link to the Creative Commons license, and indicate if changes were made.

\section{References}

Armstrong, D. M. (1993). The identification problem and the inference problem. Philosophy and Phenomenological Research, 53, 421-422.

Bacon, J. (1995). Universals and property instances. Oxford: Blackwell.

Campbell, K. (1981). The metaphysics of abstract particulars. Midwest Studies in Philosophy, 6, 477-488. (Reprinted in Properties, pp. 125-139, by D. H. Mellor \& A. Oliver Eds., 1997, Oxford: Oxford University Press).

Cargile, J. (2003). On 'Alexander's' dictum. Topoi, 22, 143-149.

Cartwright, N. (1983). How the laws of physics lie. New York: Oxford University Press.

Cartwright, N. (1999). The Dappled world: A study of the boundaries of science. Cambridge: Cambridge University Press.

Chakravartty, A. (1998). Semirealism. Studies in History and Philosophy of Science, 29, 391-408.

Chakravartty, A. (2007). A metaphysics for scientific realism: Knowing the unobservable. Cambridge: Cambridge University Press.

Clark, A. (2000). A Theory of sentience. Oxford: Clarendon Press.

Clarke, S. (2001). Defensible territory for entity realism. British Journal for the Philosophy of Science, 52, $701-722$.

Cournot, A. A. (1851). Essai sur les fondements de nos connaissances et sur les caractères de la critique philosophique. Paris: Hachette.

Crane, T. (2009). Causation and determinable properties: On the efficacy of colour, shape and size. In J. Kallestrup \& J. Howhy (Eds.), Being reduced. Oxford: Oxford University Press.

Devitt, M. (1991). Realism and truth. Oxford: Blackwell. 
Devitt, M. (2008). Realism/antirealism. In S. Psillos \& M. Curd (Eds.), The Routledge companion to the philosophy of science. London: Routledge and Kegan Paul.

Dorato, M. (2000). Substantivalism, relationism and structural spacetime realism. Foundations of Physics, 30(10), 1605-1628.

Einstein, A. (1934). On the method of theoretical physics. Philosophy of Science, 1, 163-169.

Eriksson, L., Johansson, E., Kettaneh-Wold, N., Trygg, J., Wikström, C., \& Wold, S. (2006). Multi- and megavariate data analysis, Part I (2nd Revised and (Enlarged ed.). Umeå: Umetrics AB.

Gelfert, A. (2003). Manipulative success and the unreasl. International Studies in the Philosophy of Science, $17,245-263$.

Giere, R. N. (1988). Explaining science: A cognitive approach. Chicago: University of Chicago Press.

Gillett, C., \& Rives, B. (2005). The non-existence of determinables: Or, a World of absolute determinates as default hypothesis. Nous, 39, 483-504.

Goodman, N. (1955). Fact, fiction and forecast. Cambridge, MA: Harvard University Press.

Goodman, N. (1978). Ways of worldmaking. Indianapolis: Hackett.

Hacking, I. (1982). Experimentation and scientific realism. Philosophical Topics, 13, 71-87.

Hacking, I. (1983). Representing and intervening. Cambridge: Cambridge University Press.

Hacking, I. (1989). Extragalactic reality: The case of gravitational lensing. Philosophy of Science, 56, 555-581.

Hacking, I. (1990). Natural kinds. In R. Barrett \& R. B. Gibson (Eds.), Perspectives on Quine. Oxford: Blackwell.

Hacking, I. (1991). A Tradition of Natural Kinds. Philosophical Studies, 61, 109-126.

Hacking, I. (2007a). Natural kinds: Rosy Dawn, scholastic Twilight. In A. O'Hear (Ed.), The philosophy of science (Royal Institute of Philosophy Supplements (Vol. 61, pp. 203-239). Cambridge: Cambridge University Press.

Hacking, I. (2007b). Putnam's theory of natural kinds and their names is not the same as Kripke's. Principia: Revista Internacional de Epistemologica (Florianopolis, Brazil), 11, 1-24.

Hacking, I. (2015). Natural kinds, hidden structures, and pragmatic instincts. In R. Auxier (Ed.), The philosophy of Hilary Putnam (pp. 337-357). Peru, IL: Open Court.

Hardin, C. L., \& Rosenberg, A. (1982). In defence of convergent realism. Philosophy of Science, 49, 604-615.

Jolliffe, I. (2002). Principal component analysis. New York: Springer.

Kim, J. (1993). Supervenience and mind. Cambridge: Cambridge University Press.

Kripke, S. (1972). Naming and necessity. Cambridge, MA: Harvard University Press.

Ladyman, J. (1998). What is structural realism? Studies in History and Philosophy of Science, 29, 409-424.

Laudan, L. (1981). A confutation of convergent realism. Philosophy of Science, 48, 19-48.

Laudan, L. (1984). Discussion: Realism without the real. Philosophy of Science, 51, 156-162.

Lewis, D. (1983). New work for a theory of universals. Australasian Journal of Philosophy, 61, 343-377.

Lewis, D. (2001). Redefining 'intrinsic'. Philosophy and Phenomenological Research, 63, 381-398.

Lyons, T. D. (2003). Explaining the success of a scientific theory. Philosophy of Science, 70, 891-901.

Macpherson, F. (2014). The space of sensory modalities. In D. Stokes, et al. (Eds.), Perception and its modalities. Oxford: Oxford University Press.

Massimi, M. (2004). Non-defensible middle ground for experimental realism: Why we are justified to believe in colored quarks. Philosophy of Science, 71, 36-60.

Mayr, E. (1959/1994). Typological versus population thinking. In B. J. Meggers (Ed.), Evolution and anthropology (pp. 409-412). Washington: The Anthropological Society of America.

McMullin, E. (1984). A case for scientific realism. In J. Leplin (Ed.), Scientific realism. Berkeley: University of California Press.

Morrison, M. (1990). Theory, intervention and realism. Synthese, 82, 1-22.

Musgrave, A. (1988). The ultimate argument. In R. Nola (Ed.), Relativism and realism in science (pp. 229-252). Dordrecht: Kluwer.

Musgrave, A. (1996). Realism, truth, and objectivity. In R. S. Cohen, R. Hilpinen, \& Q. Renzong (Eds.), Realism and anti-realism in the philosophy of science (pp. 19-44). Dordrecht: Kluwer.

Nanay, B. (2009). The properties of singular causation. The Monist, 92, 113-135.

Nanay, B. (2010a). Population thinking as trope nominalism. Synthese, 177, 91-109.

Nanay, B. (2010b). A modal theory of function. Journal of Philosophy, 107, 412-431.

Nanay, B. (2011a). What if reality has no architecture? The Monist, 94, 181-197. 
Nanay, B. (2011b). Three ways of resisting essentialism about natural kinds. In J. K. Campbell \& M. H. Slater (Eds.), Carving nature at its joints. Topics in contemporary philosophy (Vol. 8, pp. 175-197). Cambridge, MA: MIT.

Nanay, B. (2013). Singularist semirealism. British Journal for the Philosophy of Science, 64, 371-394.

Newton-Smith, W. (1978). The underdetermination of theory by data. Proceedings of the Aristotelian Society (Supplementary), 52, 71-91.

Pearson, K. (1901). On lines and planes of closest fit to systems of points in Space. Philosophical Magazine, 2(11), 559-572.

Psillos, S. (1999). Scientific realism: How science tracks truth. London: Routledge.

Psillos, S. (2008). Cartwright's realist toil. In S. Hartmann, C. Hoefer, \& L. Bovens (Eds.), Nancy Cartwright's philosophy of science (pp. 167-194). London: Routledge.

Putnam, H. (1975). The meaning of 'meaning'. In K. Gunderson (Ed.) Language, mind and knowledge. Minnesota studies in the philosophy of science (Vol. 7). Minneapolis, MN: University of Minnesota Press. (Reprinted from Mind, language and reality. Philosophical Papers, Vol. 2, pp. 215-271, by H. Putnam, Ed., 1975, Cambridge: Cambridge University Press.)

Quine, W. V. (1969). Natural kinds. In W. V. Quine (Ed.), Ontological relativity and other essays (pp. 114-138). New York: Columbia University Press.

Resnik, D. (1994). Hacking's experimental realism. Canadian Journal of Philosophy, 24, 395-412.

Rowbottom, D. (2010). Evolutionary epistemology and the aim of science. Australasian Journal of Philosophy, 88, 209-225.

Shapere, D. (1993). Astronomy and anti-realism. Philosophy of Science, 60, 134-150.

Shoemaker, S. (1979). Causality and properties. Identity, cause, and mind (pp. 206-233). Cambridge: Cambridge University Press.

Smart, J. J. C. (1968). Between science and philosophy. New York: Random House.

Stanford, P. K. (2000). An antirealist explanation of the success of science. Philosophy of Science, 67, $266-284$.

Taylor, B. (1993). On natural properties in metaphysics. Mind, 102, 81-100.

Taylor, B. (2004). Transworld similarity and transworld belief. Australasian Journal of Philosophy, 82, 213-225.

Van Fraassen, B. (1980). The scientific image. Oxford: Oxford University Press.

Williams, D. C. (1953). On the elements of being. Review of Metaphysics, 7(3-18), 171-192.

Worrall, J. (1989). Structural realism: The best of both worlds? Dialectica, 43, 99-124.

Yablo, S. (1992). Mental causation. Philosophical Review, 101, 245-280. 